\title{
Total plasma magnesium, zinc, copper and selenium concentrations in type-I and type-II diabetes
}

\author{
Amélie I. S. Sobczak • Fiona Stefanowicz • Samantha J. Pitt • Ramzi A. Ajjan • \\ Alan J. Stewart 10
}

Received: 19 December 2018/Accepted: 29 December 2018/Published online: 22 January 2019

(C) The Author(s) 2019

\begin{abstract}
Glycemia and insulin resistance are important regulators of multiple physiological processes and their dysregulation has wide-ranging consequences, including alterations in plasma concentrations of metal micronutrients. Here, magnesium, zinc, copper, selenium and glycated albumin (HbAlc) concentrations and quartile differences were examined in 45 subjects with type-I diabetes (T1DM), 54 subjects with type-II diabetes (T2DM) and 62 control subjects in order to assess potential differences between sexes and between T1DM and T2DM. Plasma magnesium concentration was decreased in T1DM subjects, with the second, third and fourth quartiles of magnesium concentrations associated with the absence of T1DM. This effect was observed in females but not males. In T2DM, the highest quartile of selenium concentrations and the third quartile of copper concentrations
\end{abstract}

A. I. S. Sobczak · S. J. Pitt · A. J. Stewart $(\bowtie)$ School of Medicine, University of St Andrews, Medical and Biological Sciences Building, St Andrews, Fife KY16 9TF, UK

e-mail: ajs21@st-andrews.ac.uk

F. Stefanowicz

Scottish Trace Element and Micronutrient Diagnostic and Research Laboratory, Department of Clinical Biochemistry, NHS Greater Glasgow and Clyde, Glasgow, UK

\section{R. A. Ajjan}

Leeds Institute of Cardiovascular and Metabolic Medicine, University of Leeds, Leeds, UK associated with the absence of diabetes in males. The highest quartile of magnesium concentrations was associated with the absence of T2DM in males but not females. HbA1c correlated with plasma concentrations of magnesium (negatively, in both sexes together in T1DM and T1DM males), copper (positively, in T1DM males and in both sexes together in T2DM), selenium (positively, in both sexes together in T1DM and T2DM, and T2DM females) and with zinc/copper ratio (negatively, in both sexes together in T1DM and T2DM). This study shows that plasma magnesium concentration is altered to the highest degree in T1DM, while in T2DM, plasma selenium and copper concentrations are significantly affected. This work increases our understanding of how T1DM and T2DM affects plasma metal concentrations and may have future implications for diabetes management.

Keywords Diabetes $\cdot \mathrm{HbA1c} \cdot \mathrm{ICP}-\mathrm{MS} \cdot$ Metal homeostasis $\cdot$ Zinc/copper ratio

$\begin{array}{ll}\text { Abbreviations } \\ \text { CI } & \text { Confidence interval } \\ \text { HbA1c } & \text { Glycated haemoglobin } \\ \text { ICP- } & \text { Inductively-coupled plasma-mass } \\ \text { MS } & \text { spectrometry } \\ \text { OR } & \text { Odds ratio } \\ \text { Q } & \text { Quartile } \\ \text { T1DM } & \text { Type-I diabetes mellitus } \\ \text { T2DM } & \text { Type-II diabetes mellitus }\end{array}$




\section{Introduction}

Diabetes is mainly divided into two types. In type-I diabetes (T1DM), the $\beta$-cells of the islets of Langerhans in the pancreas responsible for producing insulin are lost, typically from an attack from the immune system, causing an insulin deficiency in the body. In type-II diabetes (T2DM), cells become resistant to insulin signalling, failing to respond to it sufficiently. This is combined with either normal or increased insulin levels but can also develop into insulin deficiency through a relative loss of the insulin storage function of $\beta$-cells. Glucose levels in the body are important, as directly or indirectly they regulate many physiological processes, including glucose, glycogen metabolism. It also acts to control food intake (satiety) and maintaining long-term body weight but also regulates inflammation, vasodilatation and basic cell growth and replication. Thus, mishandling of glucose has wide-ranging consequences in the body. Among them is an alteration in the total plasma concentrations of micronutrients including some metal ions (Kaur and Henry 2014). This is thought to be caused by numerous factors, which include increased fluid loss from the body, an increased demand for micronutrients due to altered protein metabolism as well as defective metal transport due to oxidative stress (Kaur and Henry 2014; Maret 2017).

Variations in plasma metal concentrations in diabetes have been extensively studied in different populations. However there is a great heterogeneity in the data, with both higher and lower levels of the same metals having been reported (e.g. zinc and selenium) (Wang et al. 2016; Sanjeevi et al. 2018). Several meta-analyses have been performed in order to find a consensus on whether levels of some metals are higher or lower in diabetes (Wang et al. 2016; Sanjeevi et al. 2018). Analyses of quartiles of selenium concentrations yielded interesting results, with both the lowest and highest quartiles being associated with T2DM (Wang et al. 2016). Sex differences have also been shown to be of some importance with higher levels of copper reported in females with T1DM but not males (Ruiz et al. 1998). In addition, glycated haemoglobin (HbA1c) level as an indication of diabetes management was found to correlate with several plasma metal concentrations, including zinc, copper and magnesium and also to the zinc/copper ratio (Naka et al. 2013; Ramadass et al. 2015; Atari-Hajipirloo et al. 2016).

Here, we have examined the total plasma concentrations of zinc, copper, magnesium and selenium in patients with T1DM and T2DM and in controls, assessing the correlation between quartiles of metal cations concentrations and diabetes, as well as the influence of sex and diabetes management through blood HbA1c levels. Plasma metal concentrations and potential sex differences in those concentrations have not been thoroughly examined both in T1DM and in T2DM in the same study before. The results indicate that magnesium deficiency is particularly important in T1DM while elevated copper and selenium deficiency in females are more important in T2DM. A better understanding of those effects could lead to a better understanding of metal micronutrient handling and to better management and treatment of T1DM and T2DM.

\section{Methods}

Samples collection and treatment

A total of 45 patients with T1DM, 54 patients with $\mathrm{T} 2 \mathrm{DM}$ and 62 controls were recruited from Leeds Teaching Hospital Trust. Plasma samples from subjects with either T1DM or T2DM and controls were collected following approval by the local Research Ethics Committee in Leeds and after obtaining written informed consent. For all subjects, baseline fasting blood samples were collected in lithium heparin coated tubes. Plasma was then separated within $2 \mathrm{~h}$ of collection by centrifugation at $2400 \times g$ for $20 \mathrm{~min}$ at $4{ }^{\circ} \mathrm{C}$. Samples were snap frozen in liquid nitrogen and stored at $-40{ }^{\circ} \mathrm{C}$ until analysis.

Inductively-coupled plasma-mass spectrometry (ICP-MS)

Single element stock solutions (Centripure, Merck, UK) traceable to the United States National Institute of Standards and Technology (NIST) were used for calibration standards and internal standards. All calibration standards were prepared using a solution of $2 \% \mathrm{v} / \mathrm{v}$ butan-1-ol (Sigma Aldrich, USA), $0.05 \%$ w/v EDTA (Sigma Aldrich), 0.05\% v/v Triton-X-100 (Sigma Aldrich), 1\% v/v ammonia (Romil, UK) in 
18.2 Mohm reverse osmosis deionised water (Elga Maxima High Wicombe, UK). Lithium heparin plasma samples were diluted 1 in 10 with the same solution used to prepare calibration standards with $25 \mathrm{ppb}$ germanium. ClinChek ${ }^{\circledR} 1$ \& 2 (RECIPE, Germany) and Seronorm ${ }^{\mathrm{TM}} 1$ (SERO, Norway) human serum certified reference materials were used to demonstrate accuracy. ClinChek ${ }^{\circledR} 1$ and 2 are materials with consensus values while Seronorm ${ }^{\mathrm{TM}}$ is traceable to a National Institute of Standard Technology (NIST) certified reference material.

Copper, zinc, selenium and magnesium analyses were performed simultaneously using an Agilent 7900 ORS-ICP-MS (Agilent Technologies, Santa Clara, California, USA). The instrument was controlled using Mass Hunter software (version 4.1, Agilent Technologies). Argon was used to form the plasma (CryoServices Ltd, purirty: 99.9\%). Polyatomic interferences for copper, zinc and magnesium were removed through collision induced dissociation and kinetic energy discrimination using helium gas (Air Products and Chemicals, Inc, purity 99.9\%). Polyatomic and doubly charged interferences for selenium were removed using a charge exchange reaction by using the collision cell with hydrogen. The concentration of all elements was measured three times within a single run using the central $0.05 \mathrm{~m} / \mathrm{z}$ of the peak. The ICP-MS was equipped with an CETAC ASX-500 series autosampler (Teledyne CETAC, Omaha, USA), an Integrated Sample Introduction System and Discrete Sampler-3 (ISIS-DS, Agilent Technologies) and a G32992A re-circulating chiller (Polyscience, Illinois, USA). The ISIS-DS was fitted with a Quartz Scott-Type, Double-Pass Spray Chamber (Agilent Technologies), a glass micromist nebuliser (Agilent Technologies) and a sample loop. The sample loop was prepared in-house using $0.8 \mathrm{~mm}$ internal diameter and PTFE sample tubing (Agilent Technologies). A quartz torch with $2.5 \mathrm{~mm}$ internal diameter was used (Agilent Technologies). Nickel sampling and skimmer cones were used at all times (Agilent Technologies). All instrument parameters were optimised daily by performing an auto-tune while aspirating a tuning solution containing $10 \mathrm{ppb}$ lithium, yttrium, cobalt, cerium and thallium. Typical instrument parameters are shown in Table 1. Three certified reference materials (Seronorm 1 and ClinCheck 1 and 2) with assigned values and ranges were used to demonstrate the accuracy of the method used to determine the concentrations of $\mathrm{Mg}, \mathrm{Cu}, \mathrm{Zn}$ and $\mathrm{Se}$ in human plasma (Table 2). The mean for all measurands were within the assigned range for all materials and had satisfactory recoveries ranging between 96.4 and $107 \%$. The precision of the method, represented by coefficient of variation, was also satisfactory with values less than or equal to $3 \%$. All metal concentrations in plasma were compared to the glycated haemoglobin concentrations which were measured in the samples as a routine test.

Statistical analysis and representation

Data are presented as mean \pm standard error of the mean (SEM). Graphs were generated and statistical analysis was performed using Prism 7.0 (GraphPad Software, La Jolla, CA). Differences between groups were analysed using multiple Student's t-tests or analysis of variance, while correlations between linear variants were analysed with Pearson's correlation. The data was also separated into quartiles and odd ratios were calculated. Significance threshold was set at $\mathrm{p} \leq 0.05$.

\section{Results and discussion}

Total plasma zinc, copper, magnesium, selenium concentrations and zinc/copper ratios in T1DM and $\mathrm{T} 2 \mathrm{DM}$

ICP-MS was used to determine the total plasma concentrations of zinc, copper, magnesium and selenium in subjects with T1DM or T2DM and in their respective age-matched controls. The zinc/copper ratio was also calculated in all samples. Table 3 summarises the demographic characteristics of our population as well as the mean plasma HbA1c and metal concentrations values in each group. As expected, t-tests indicate that subjects with T1DM or T2DM have higher plasma concentrations of HbA1c than controls. Both diabetes groups also had higher mean BMI values than controls, while the T2DM group also has a higher percentage of male subject than the controls. Mean plasma zinc, copper and selenium concentrations were not significantly altered in subjects with either T1DM or T2DM compared to controls. Whereas the mean plasma magnesium concentration was significantly lower in subjects with 
Table 1 ICP-MS instrument parameters

\begin{tabular}{ll}
\hline Parameter & Setting \\
\hline Isotopes monitored $(\mathrm{m} / \mathrm{z})$ & $\mathrm{Cu} 63, \mathrm{Zn} \mathrm{66,} \mathrm{Se} \mathrm{78} \mathrm{and} \mathrm{Mg} \mathrm{24}$ \\
RF power (W) & 1550 \\
RF matching & 1.70 \\
Sampling depth (mm) & 10 \\
Carrier gas (L/min) & 1.05 \\
Make up gas L/min) & 0.0 \\
Spray chamber temperature $\left({ }^{\circ} \mathrm{C}\right)$ & 2 \\
He octopole reaction system flow $(\mathrm{mL} / \mathrm{min})$ & 5.0 \\
Nebuliser pump (rps) & 0.1 \\
\hline
\end{tabular}

Table 2 Accuracy of the ICP-MS method and details of the concentration of trace elements in each material (coefficient of variation and recovery)

\begin{tabular}{lllllll}
\hline Measurand & Specimen & Assigned value & Range & Mean & CV (\%) & Recovery $(\%)$ \\
\hline Plasma Mg $(\mathrm{mM})$ & ClinCheck 1 & 0.64 & $0.58-0.71$ & 0.62 & 1.8 & 97.6 \\
& ClinCheck 2 & 1.21 & $1.09-1.33$ & 1.17 & 1.5 & 96.4 \\
Plasma Cu $(\mu \mathrm{M})$ & Seronorm1 & 17.1 & $15.7-18.7$ & 17.0 & 1.8 & 99.6 \\
& ClinCheck 1 & 10.9 & $8.7-13.1$ & 10.7 & 1.3 & 97.8 \\
& ClinCheck 2 & 19.1 & $15.4-23.0$ & 19.0 & 1.4 & 98.8 \\
Plasma Zn $(\mu \mathrm{M})$ & Seronorm1 & 16.8 & $14.6-19.0$ & 17.8 & 3.0 & 107 \\
& ClinCheck 1 & 17.7 & $14.2-21.3$ & 17.6 & 0.8 & 99.2 \\
Plasma Se $(\mu \mathrm{M})$ & ClinCheck 2 & 23.2 & $18.8-28.3$ & 24.2 & 1.3 & 104.2 \\
& Seronorm1 & 1.10 & $0.96-1.25$ & 1.09 & 0.8 & 98.8 \\
& ClinCheck 1 & 1.03 & $0.82-1.24$ & 1.06 & 0.7 & 1.2 \\
& ClinCheck 2 & 1.52 & $1.22-1.82$ & 1.57 & 1.2 & 104 \\
\hline
\end{tabular}

T1DM than in controls but not with T2DM, while the plasma zinc/copper ratio was significantly higher in T2DM subjects than in controls, but this was not the case in T1DM.

The data from each of the two diabetes groups, (T1DM and T2DM subjects; each with their respective age-matched controls) were split into quartiles for each metal, defined as four groups delimited by $25 \%$, median and $75 \%$ of highest values in each of the groups. The odd ratios (ORs) of a subject in a specific quartile having diabetes were calculated (Table 4). No significant difference in total plasma zinc concentrations was observed between either the T1DM or the T2DM groups and their age-matched controls. This is contrary to two previous reports-a meta-analysis accumulating 20,183 T2DM subjects and a study with 51 T1DM subjects both showing that zinc concentration is lower in diabetes ( $\mathrm{Li}$ et al. 2018; Sanjeevi et al.
2018). Despite previous reports of both higher and lower zinc concentrations being associated with T2DM, no significance could be gained by examining quartiles of zinc concentrations (Sanjeevi et al. 2018). In T2DM, the ORs of having diabetes in the second (Q2), third (Q3) and fourth (Q4) copper quartile groups were respectively 0.031 [95\% confidence interval (CI) $0.080-1.275, \mathrm{p}>0.05], 0.193(95 \% \mathrm{CI}$ $0.051-0.966, \quad \mathrm{p}<0.05)$ and $0.276 \quad(95 \% \quad \mathrm{CI}$ $0.070-1.154, \mathrm{p}>0.05)$ compared with the first (Q1) quartile group. The absence of a clear difference between T2DM subjects and controls (with only Q3 being significantly associated with the absence of diabetes) can be explained by the mean plasma copper concentration being very low in our T2DM group and high in our age-matched controls, almost enough to be significantly higher in the controls $(\mathrm{p}=0.0698)$, whereas a meta-analysis involving 20,183 T2DM 
Table 3 Demographic characteristics of the studied population and mean plasma HbA1c and metal concentrations in each group

\begin{tabular}{|c|c|c|c|c|c|c|}
\hline Characteristics & $\begin{array}{l}\text { T1DM } \\
\text { subjects } \\
(n=45)\end{array}$ & $\begin{array}{l}\text { T1DM age- } \\
\text { matched } \\
\text { controls } \\
(n=47)\end{array}$ & $\begin{array}{l}t \text { test between } \\
\text { T1DM and age- } \\
\text { matched controls }\end{array}$ & $\begin{array}{l}\text { T2DM } \\
\text { subjects } \\
(n=54)\end{array}$ & $\begin{array}{l}\text { T2DM age- } \\
\text { matched } \\
\text { controls } \\
(n=18)\end{array}$ & $\begin{array}{l}\mathrm{t} \text {-test between } \\
\mathrm{T} 2 \mathrm{DM} \text { and age- } \\
\text { matched controls }\end{array}$ \\
\hline $\begin{array}{l}\text { Age } \\
\quad(\text { years } \pm \mathrm{SD})\end{array}$ & $26.3 \pm 6.8$ & $24.3 \pm 6.2$ & ns & $61.1 \pm 7.6$ & $57.1 \pm 8.9$ & ns \\
\hline Males, $n(\%)$ & $26(58)$ & $24(51)$ & ns & $47(87)$ & $9(50)$ & $* * *$ \\
\hline \multicolumn{7}{|l|}{ BMI } \\
\hline $\begin{array}{l}\text { BMI (kg/ } \\
\left.\mathrm{m}^{2} \pm \mathrm{SD}\right)\end{array}$ & $24.6 \pm 3.6$ & $23.0 \pm 3.0$ & $*$ & $32.6 \pm 5.3$ & $25.0 \pm 3.2$ & $* * *$ \\
\hline $\begin{array}{l}\mathrm{n}(\%) \text { for } \\
\quad \mathrm{BMI}<25\end{array}$ & $24(53)$ & $38(81)$ & - & $2(4)$ & $10(59)$ & - \\
\hline $\begin{array}{c}\mathrm{n}(\%) \text { for } \mathrm{BMI} \\
25 \text { to }<30\end{array}$ & $18(40)$ & $8(17)$ & - & $17(31)$ & $6(35)$ & - \\
\hline $\begin{array}{l}\mathrm{n}(\%) \text { for } \\
\quad \mathrm{BMI} \geq 30\end{array}$ & $3(7)$ & $1(2)$ & - & $35(65)$ & $1(6)$ & - \\
\hline $\begin{array}{l}\text { HbA1c conc. } \\
\text { mean } \\
(\mathrm{mM} \pm \mathrm{SD})\end{array}$ & $69.8 \pm 18.0$ & $33.5 \pm 0.7$ & $* *$ & $72.4 \pm 22.8$ & $37.6 \pm 4.2$ & $* * *$ \\
\hline $\begin{array}{l}\text { Zinc conc. } \\
\text { mean } \\
(\mu \mathrm{M} \pm \mathrm{SD})\end{array}$ & $12.80 \pm 1.50$ & $13.50 \pm 2.30$ & ns & $12.70 \pm 1.40$ & $12.38 \pm 1.69$ & ns \\
\hline $\begin{array}{l}\text { Copper conc. } \\
\text { mean } \\
(\mu \mathrm{M} \pm \mathrm{SD})\end{array}$ & $17.56 \pm 6.60$ & $16.26 \pm 5.50$ & ns & $15.49 \pm 2.78$ & $17.30 \pm 4.70$ & ns \\
\hline $\begin{array}{l}\text { Magnesium } \\
\text { conc. mean } \\
(\mathrm{mM} \pm \mathrm{SD})\end{array}$ & $0.747 \pm 0.057$ & $0.806 \pm 0.054$ & $* * *$ & $0.738 \pm 0.075$ & $0.765 \pm 0.115$ & ns \\
\hline $\begin{array}{l}\text { Selenium conc. } \\
\text { mean } \\
(\mu \mathrm{M} \pm \mathrm{SD})\end{array}$ & $1.147 \pm 0.145$ & $1.129 \pm 0.136$ & ns & $1.142 \pm 0.188$ & $1.222 \pm 0.261$ & ns \\
\hline $\begin{array}{l}\text { Zinc/copper } \\
\quad(\text { ratio } \pm \mathrm{SD})\end{array}$ & $0.813 \pm 0.273$ & $0.886 \pm 0.246$ & ns & $0.841 \pm 0.152$ & $0.751 \pm 0.187$ & $*$ \\
\hline
\end{tabular}

Significance is indicated as $* \mathrm{p}<0.05, * * \mathrm{p}<0.01$ and $* * * \mathrm{p}<0.001$

individuals has shown that plasma copper is higher in T2DM (Sanjeevi et al. 2018). There were no differences in plasma copper concentrations between quartiles in the T1DM group, contrary to a previous study (Ruiz et al. 1998). The ORs of having T1DM in the Q2, Q3, Q4 magnesium groups were 0.176 (95\% CI $0.058-0.628, \mathrm{p}<0.01), 0.1173$ (95\% CI 0.036-0.432, $\mathrm{p}<0.01)$ and, $0.086 \quad(95 \%$ CI $0.028-0.325$, $\mathrm{p}<0.001)$ compared with the Q1 group. Thus, T1DM is associated with lower plasma magnesium concentrations (Q2-Q4), as supported by a previous study (Brown et al. 1999). In T2DM, no differences in magnesium concentration were observed between quartiles. This is despite a meta-analysis involving 286,668 T2DM subjects having found an association between low dietary magnesium levels and T2DM, while another study following 12,128 non-diabetic subjects over 6 years reported an inverse relationship between serum magnesium concentrations and incidence of T2DM amongst white (but not black) participants (Kao et al. 1999; Larsson and Wolk 2007). For plasma selenium concentrations, the ORs of having T2DM in the Q2, Q3 and Q4 selenium groups were respectively 0.850 (95\% CI 0.221-3.292, $\mathrm{p}>0.05), 0.560$ (95\% CI 0.152-2.484, p > 0.05) and 0.100 (95\% CI 0.017-0.682, p < 0.01) compared with 


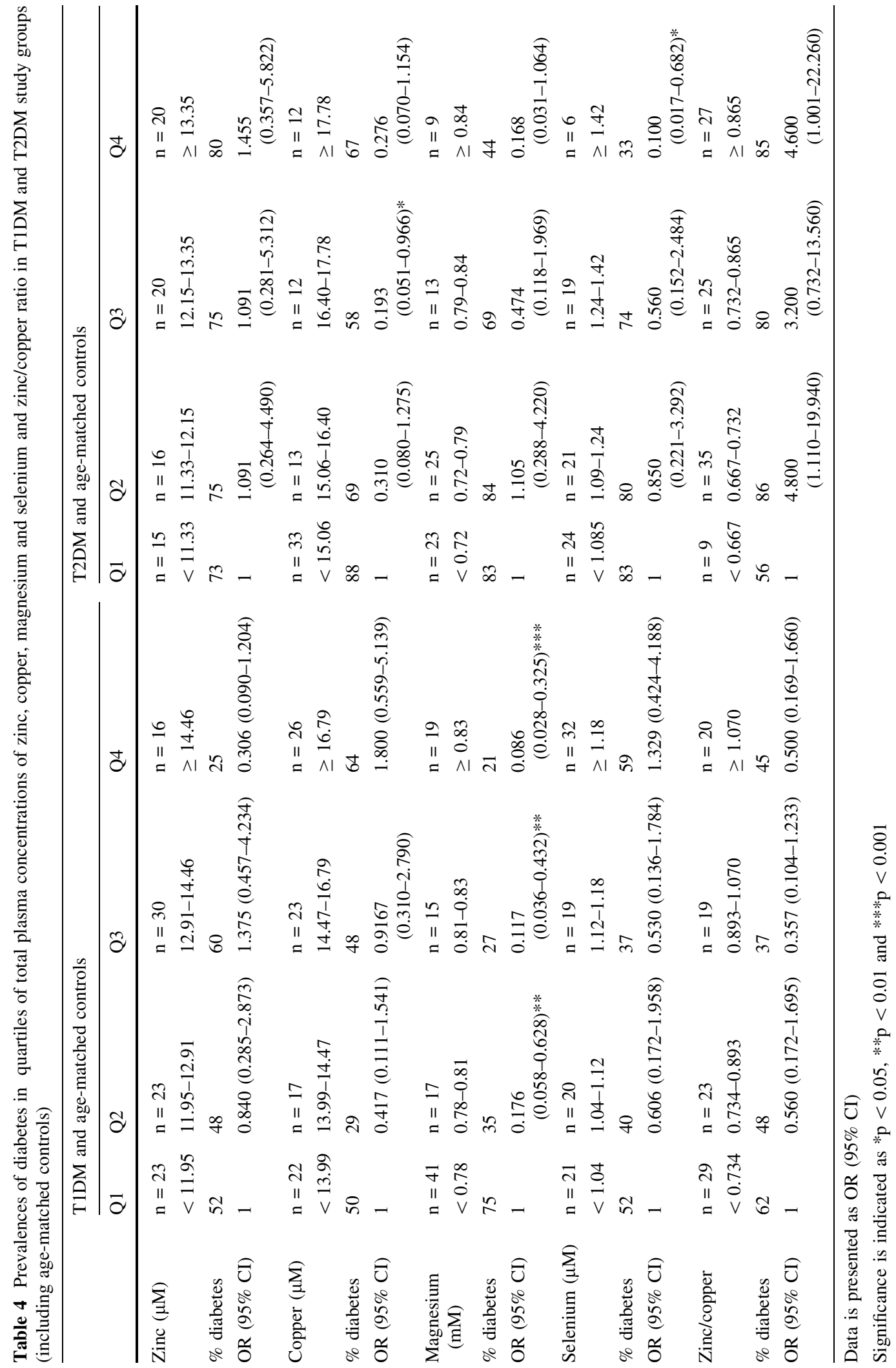


the Q1 group. Thus, low selenium concentrations were linked with T2DM. The fact that subjects in Q4 did not associate with T2DM is contrary to the findings of previously published meta-analysis based on 13,460 T2DM patients, where both Q1 and Q4 were associated with T2DM (Wang et al. 2016). No differences in plasma selenium concentrations were observed between quartiles in T1DM, although a previous study indicated that lower plasma selenium concentrations have been found in T1DM (Ruiz et al. 1998). Here we were unable to see any differences between zinc/copper ratio quartiles in either T1DM or T2DM, contrary to the higher mean ratios we measured in T2DM. Some previous publications also indicated that lower plasma zinc/copper ratios have been observed in T1DM (Lin et al. 2014) and in T2DM (AtariHajipirloo et al. 2016). The failure to detect some of these previously reported relationships in our study may be due to the number of subjects (and the resultant effect on statistical power). Thus larger cohort studies enable relatively subtle differences in plasma metal concentrations to be observed between individuals with diabetes and controls. However, those differences may not be as relevant as those that can be detected in smaller cohorts.

Differences in plasma metal concentrations between males and females with T1DM or T2DM

The influence of the sex of the subjects on plasma metal concentrations between the various groups was examined (Table 5). In our age-matched controls for the T1DM group, males had significantly higher zinc concentrations and lower copper concentrations than females, while in the T1DM group males had significantly higher zinc and magnesium concentrations and lower copper concentrations than females. The T2DM group was harder to study as there were few females in the group. However, copper concentrations were significantly lower and the zinc/copper ratio higher in males than in females. The T1DM and T2DM groups were then compared with their respective agematched controls. Magnesium concentrations were lower in males and females with T1DM than in the respective controls, while only males with T2DM had a lower magnesium concentration than their respective controls. In addition, the zinc/copper ratio was higher in males with T2DM than in the male controls.
The plasma metal concentration quartile groups described above were split according to sex (Table 6). The ORs of having T1DM in the Q2, Q3 and Q4 female magnesium quartile groups were respectively 0.000 (95\% CI $0-0.480, \mathrm{p}<0.01), 0.059$ (95\% CI $0.005-0.482, \quad \mathrm{p}<0.05)$ and $0.033 \quad(95 \% \quad \mathrm{CI}$ $0.003-0.287, \mathrm{p}<0.001)$ compared to the Q1 group. There were no differences between magnesium quartiles in T1DM males despite a lower mean having been observed compared to male controls. To our knowledge, no sex differences in mean plasma magnesium concentrations in T1DM subjects have been reported before. No significance differences in male copper quartiles or in female copper quartiles were observed in T1DM. This is contrary to a report, which found that plasma copper concentrations were higher in females with T1DM than in females controls but that this was not the case in males (Ruiz et al. 1998). However another study (with only 18 individuals and both T1DM and T2DM analysed together) reported the absence of any difference in plasma copper concentration between males and females with diabetes (Terres-Martos et al. 1998). In addition, no significant differences in male or in female zinc or zinc/copper quartiles were identified in T1DM.

The low number of females among our T2DM cohort made accurate comparison between the sexes more difficult to perform and no statistically significant differences were found with any metal when examining female subjects in the quartiles. However, when looking at males only the copper Q3, magnesium Q4 and selenium Q4 groups were associated with the absence of T2DM. The ORs of having T2DM in the Q2, Q3 and Q4 male copper quartile groups were respectively 0.167 (95\% CI $0.011-1.649, \mathrm{p}>0.05)$, $0.074(95 \%$ CI $0.006-0.625, \mathrm{p}<0.05)$ and 0.074 (95\% CI $0.005-0.842, \mathrm{p}>0.05$ ) compared to the Q1 group. In a meta-analysis of copper concentrations in T2DM, no sex differences were observed (Sanjeevi et al. 2018). The ORs of having T2DM in the Q2, Q3 and Q4 male magnesium quartile groups were respectively 0.9444 (95\% CI $0.04734-18.9, \mathrm{p}>0.05$ ), $0.1944(95 \%$ CI $0.01285-2, \mathrm{p}>0.05)$ and 0.056 (95\% CI 0.004-0.582, p < 0.05) compared to the Q1 group. Contrary to this, a previous study has found that females with T2DM were more likely to have lower magnesium concentrations than males (Kao et al. 1999). The ORs of having T2DM in the Q2, Q3 and Q4 male selenium quartile groups were respectively for 


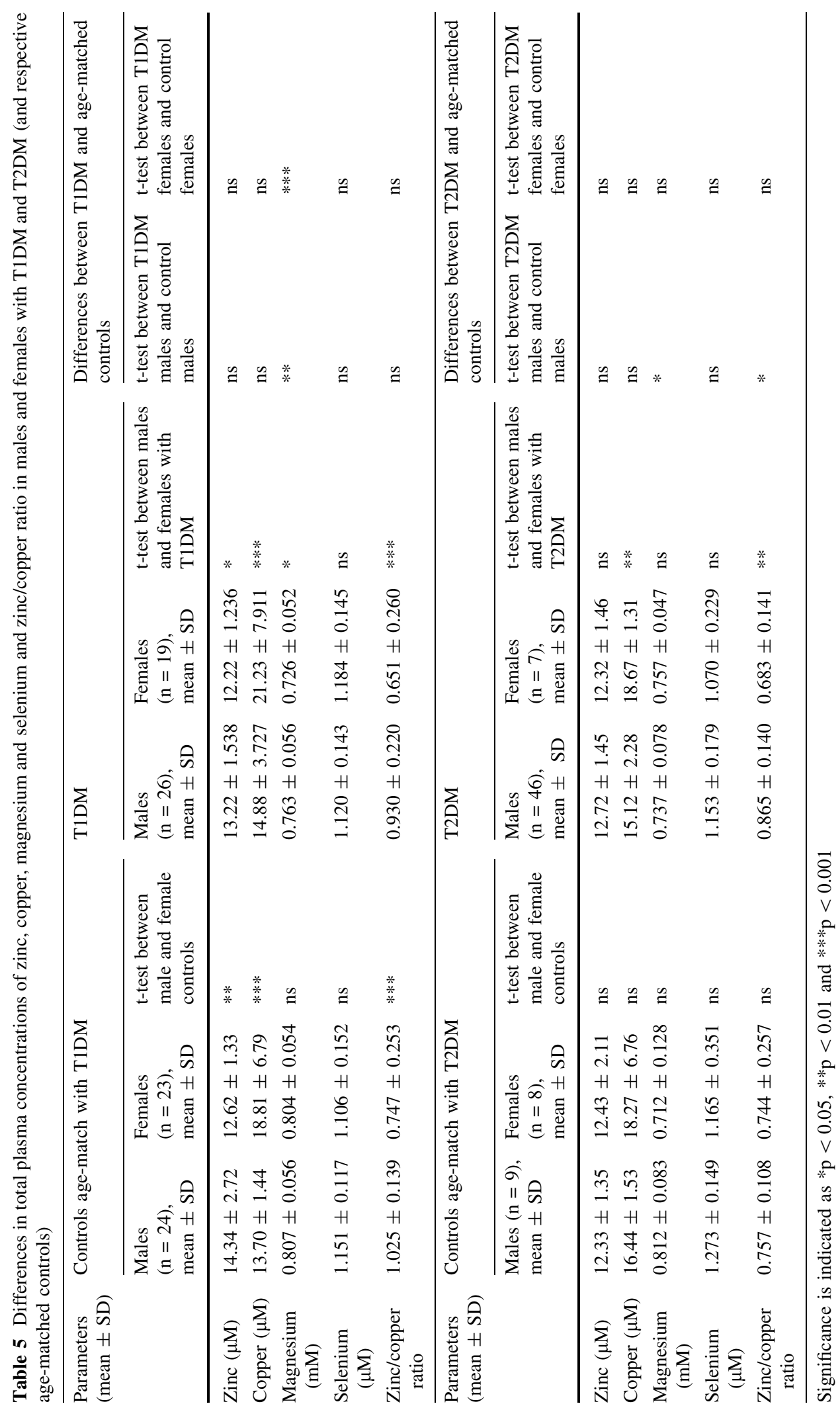




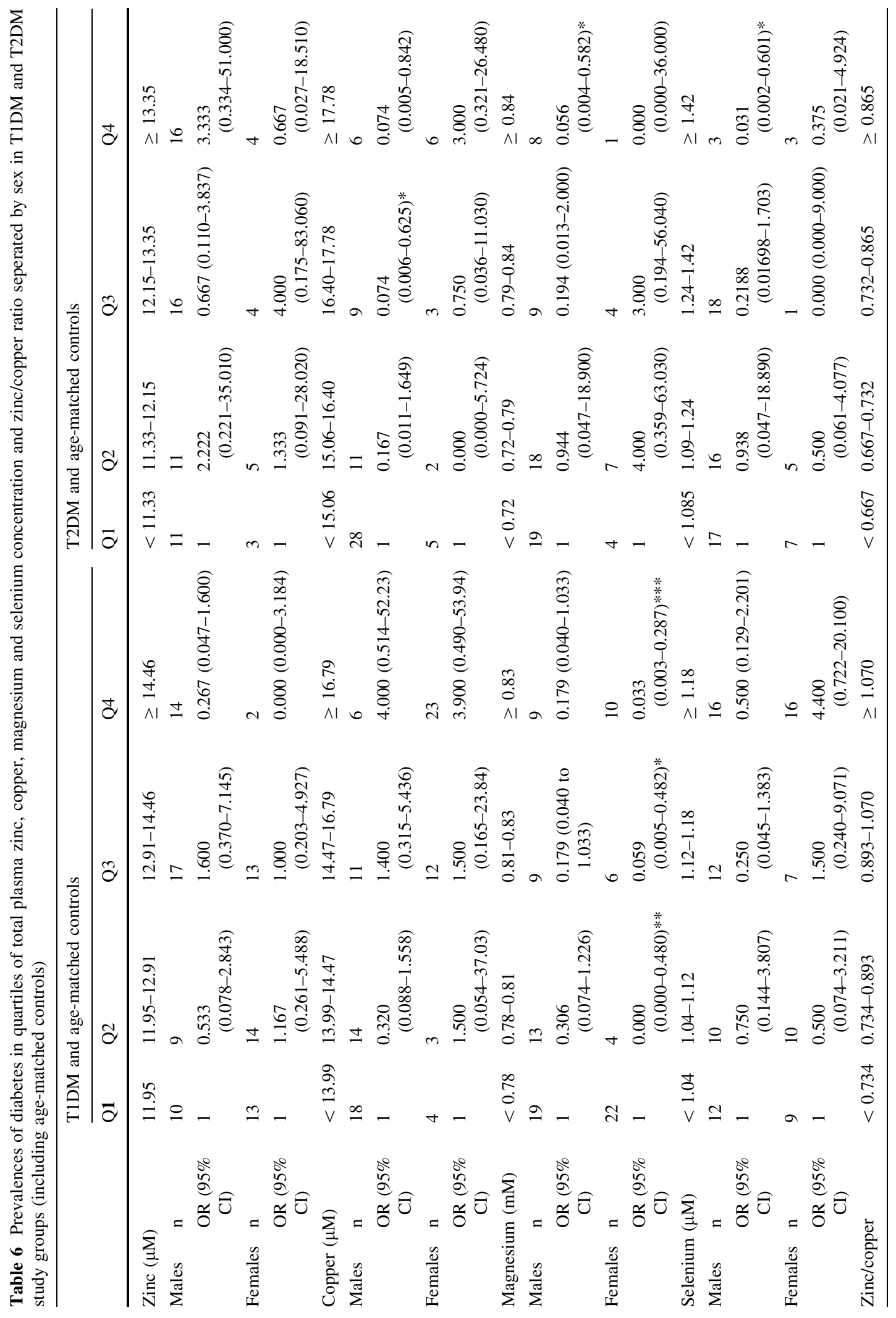




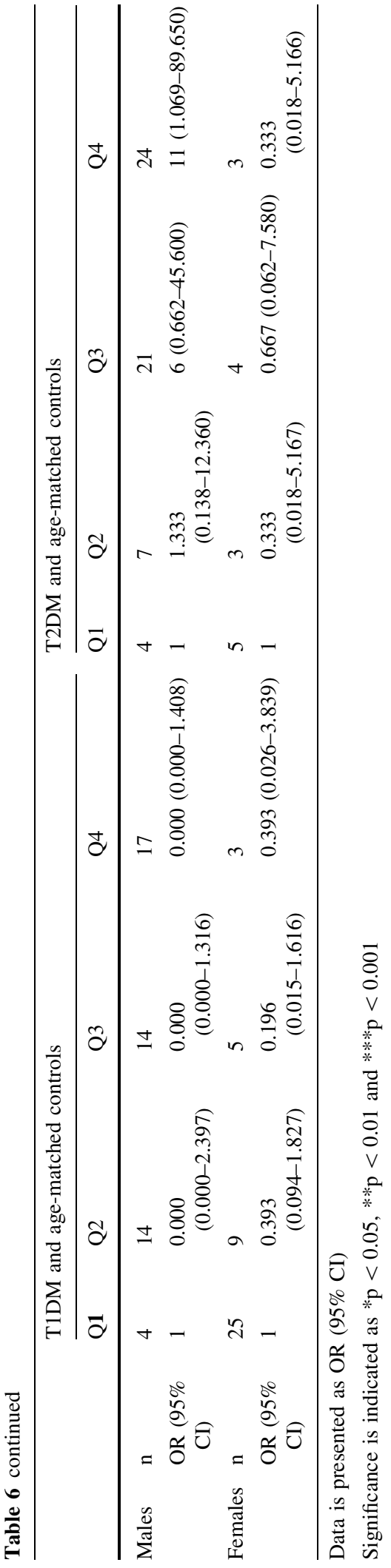

Fig. 1 Relationship between HbA1c concentration and plasma zinc, copper, magnesium and selenium concentrations as well as zinc/copper ratio in all T1DM subjects and male and female T1DM subjects. a-c HbA1c concentration vs zinc concentration, d-f HbA1c concentration vs copper concentration, gi HbA1c concentration vs magnesium concentration, $\mathbf{j}-\mathbf{l}$ HbA1c concentration vs selenium concentration and $\mathbf{m}-\mathbf{o} \mathrm{HbA} 1 \mathrm{c}$ concentration vs zinc/copper ratio. a, d, g, j, m both sexes together, b, e, h, k, $\mathbf{n}$ male subjects and $\mathbf{c}, \mathbf{f}, \mathbf{i}, \mathbf{l}, \mathbf{o}$ female subjects. Black circles were used for the data that were correlated to HbA1c concentration, while white circles were used when the relationship was not significant. HbA1c concentration was positively correlated with plasma copper concentration in males $(\mathrm{p}=0.0418)$ and with plasma selenium concentration in both sexes together $(\mathrm{p}=0.0311)$, while it was negatively correlated with plasma magnesium concentration in both sexes together $(p=0.0040)$ and in males $(p=0.0067)$ and with the zinc/copper ratio in both sexes together $(p=0.0258)$

selenium 0.938 (95\% CI $0.047-18.89, \mathrm{p}>0.05)$, 0.219 (95\% CI $0.017-1.703, \mathrm{p}>0.05), 0.031(95 \%$ CI 0.002-0.601, p < 0.05) compared to the Q1 group. Association between T2DM and selenium concentrations (too low or too high) in males but not females have been reported before (Bleys et al. 2007; Laclaustra et al. 2009; Akbaraly et al. 2010).

Relationship between plasma metal concentrations and $\mathrm{HbA} 1 \mathrm{c}$ concentration

Relationships between HbA1c concentration, as a proxy for glycemic control, and metal concentrations in subjects with T1DM (Fig. 1) or T2DM (Fig. 2) were examined. Plasma zinc concentration did not correlate with HbA1c concentration in either T1DM or T2DM, which is in accord with a previous finding in T1DM but contrary to a previous publication that has found a negative correlation (Luo et al. 2015; Lin et al. 2016). In T1DM, plasma copper concentration positively correlated with $\mathrm{HbA} 1 \mathrm{c}$ concentration in males ( $p=0.042$, Fig. 1e) but not with females or with both sexes together. In T2DM, the plasma copper concentration correlated with $\mathrm{HbA} 1 \mathrm{c}$ concentration only when considering both sexes together $(p=0.003$, Fig. 2d) but not in males or females only. Previous studies have found that plasma copper concentration do not correlate with HbA1c concentration in T1DM but positively correlates in T2DM (Ruiz et al. 1998; Atari-Hajipirloo et al. 2016). Plasma magnesium concentration negatively correlated with $\mathrm{HbA} 1 \mathrm{c}$ concentration in T1DM when looking at both sexes 
a

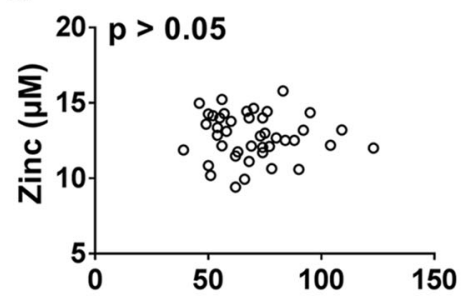

HbA1c (mM) in all subjects

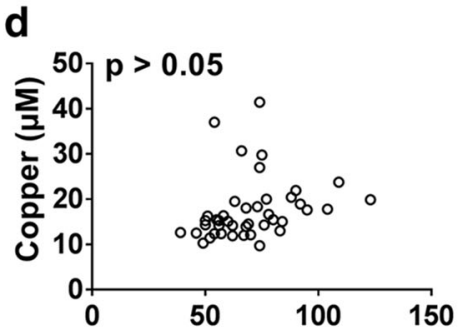

HbA1c (mM) in all subjects

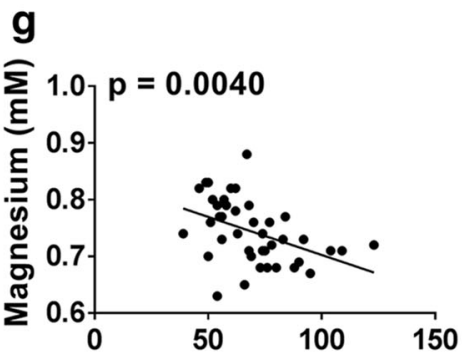

HbA1c (mM) in all subjects

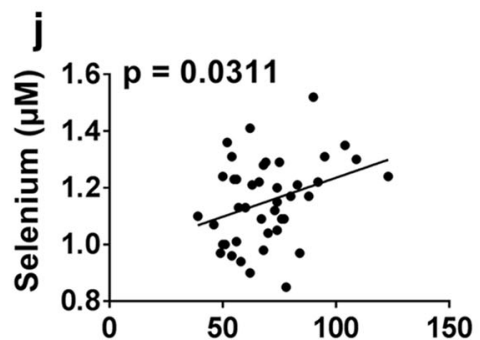

HbA1c (mM) in all subjects

m

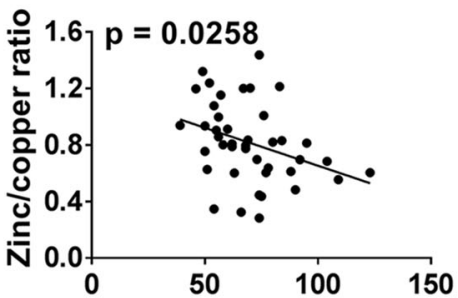

HbA1c (mM) in all subjects b
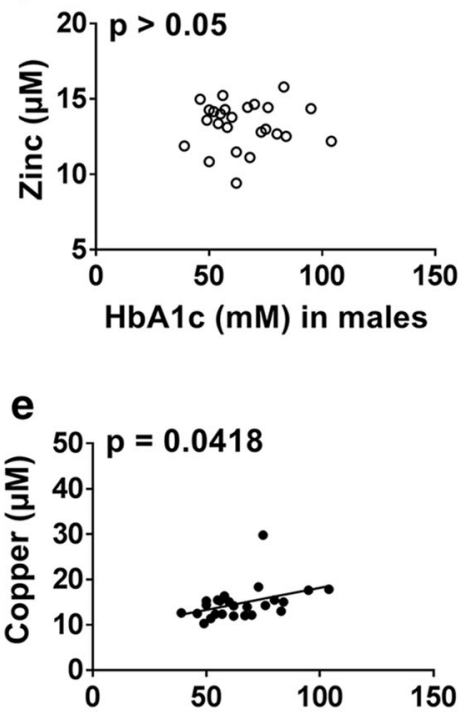

HbA1c (mM) in males

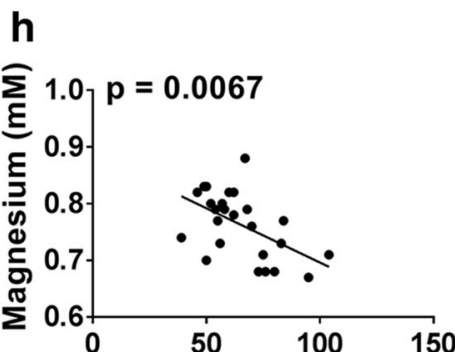

HbA1c (mM) in males

k

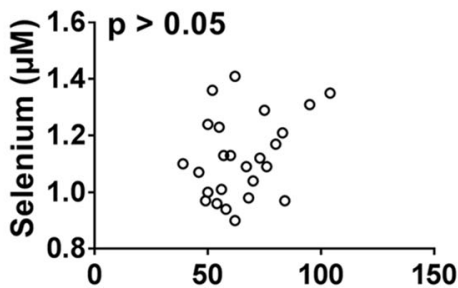

HbA1c (mM) in males

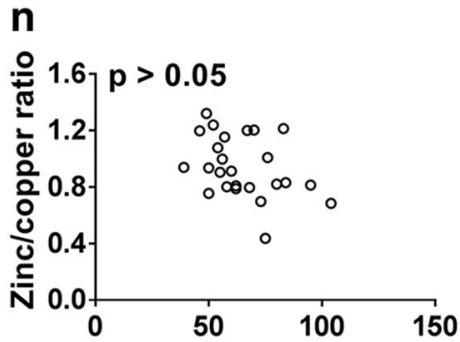

HbA1c (mM) in males
C

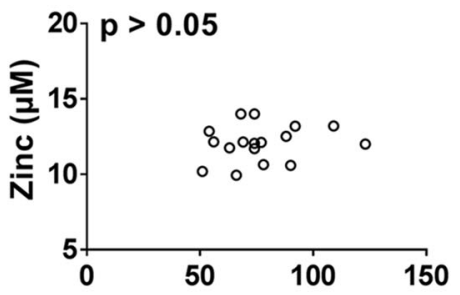

HbA1c (mM) in females

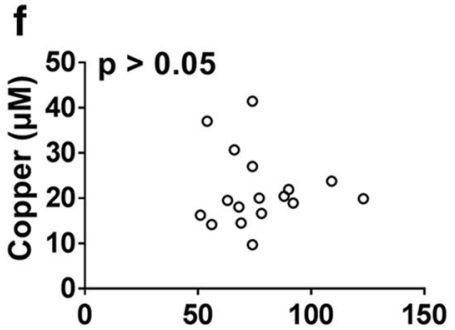

HbA1c (mM) in females

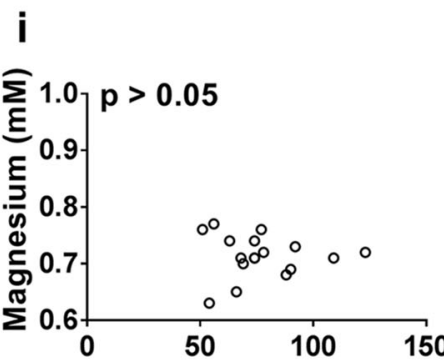

HbA1c (mM) in females
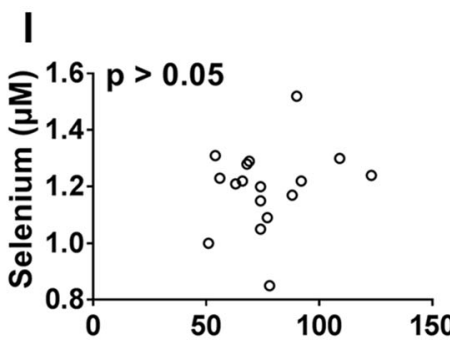

HbA1c (mM) in females

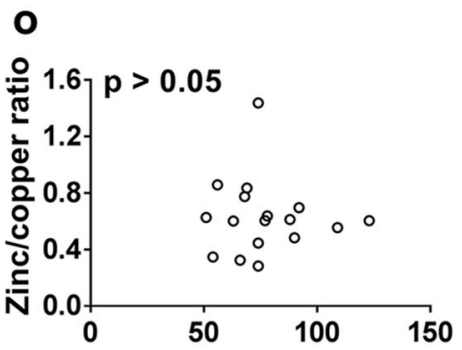

HbA1c (mM) in females 


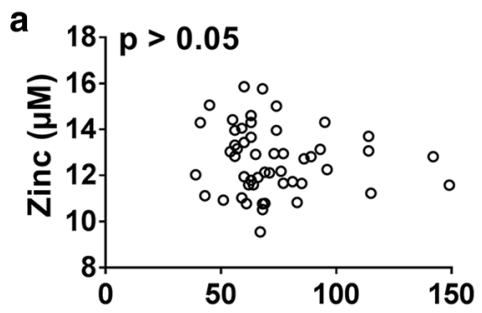

HbA1c (mM) in all subjects

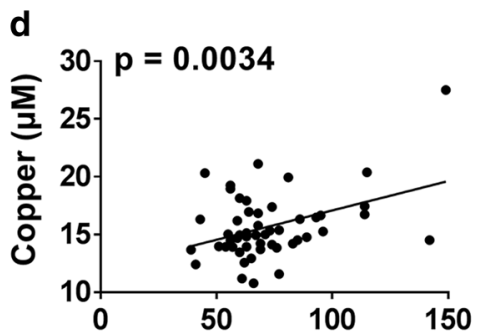

HbA1c (mM) in all subjects

g

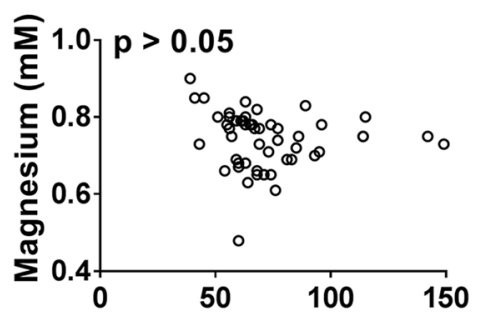

HbA1c (mM) in all subjects

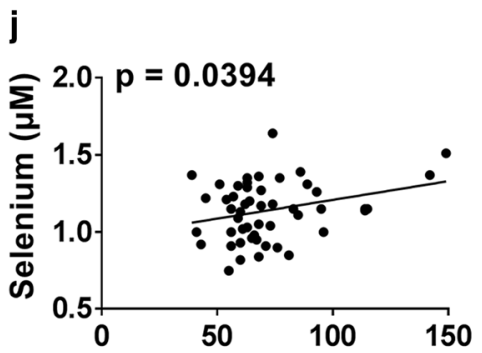

HbA1c (mM) in all subjects

m

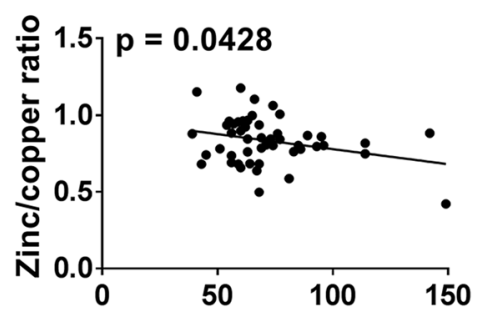

HbA1c (mM) in all subjects

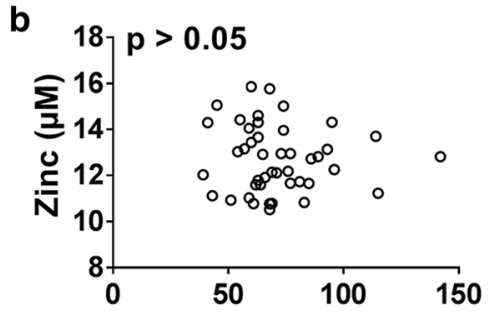

HbA1c (mM) in males

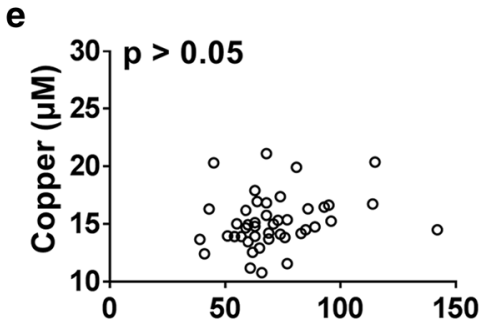

HbA1c (mM) in males

h

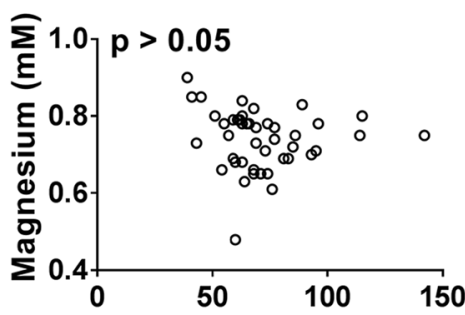

HbA1c (mM) in males

k

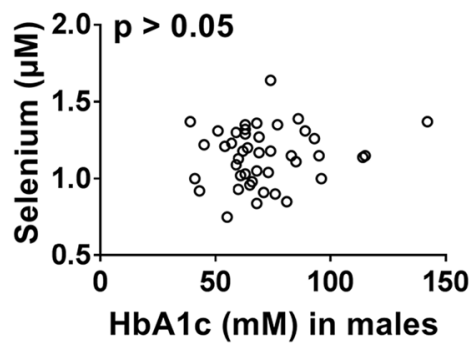

n

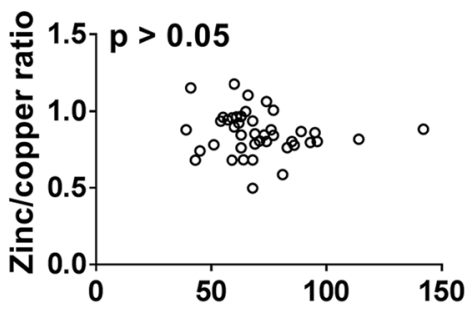

HbA1c ( $\mathrm{mM})$ in males

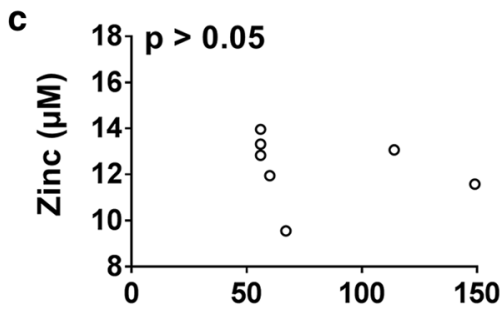

HbA1c (mM) in females

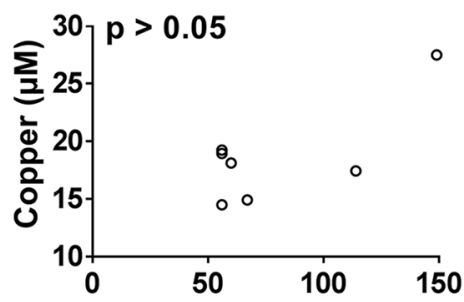

HbA1c (mM) in females

i

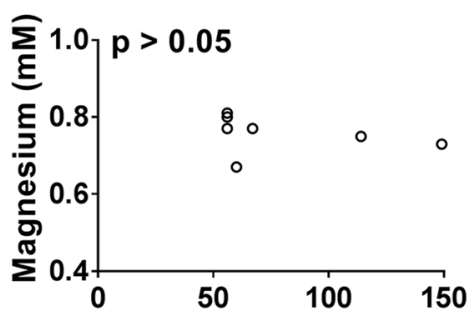

HbA1c (mM) in females

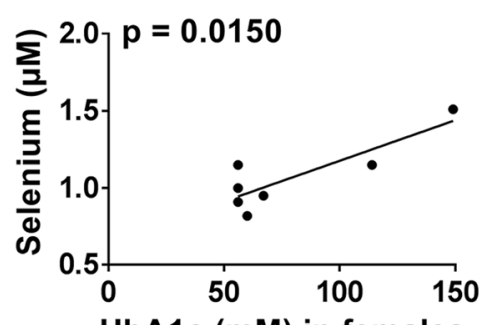

HbA1c (mM) in females

0

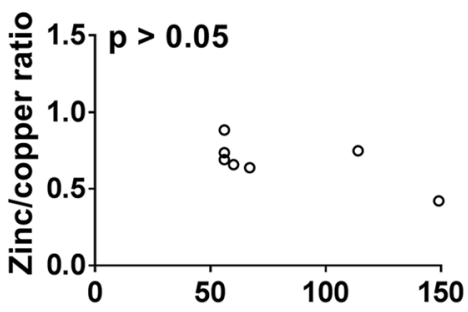

HbA1c (mM) in females 
४Fig. 2 Relationship between HbA1c concentration and plasma zinc, copper, magnesium and selenium concentrations as well as zinc/copper ratio in all T2DM subjects and male and female T2DM subjects. a-c HbA1c concentration vs zinc concentration, d-f HbA1c concentration vs copper concentration, $\mathbf{g}_{-}$ i HbA1c concentration vs magnesium concentration, $\mathbf{j}-\mathbf{l}$ HbA1c concentration vs selenium concentration and m-o HbA1c concentration vs zinc/copper ratio. a, $\mathbf{d}, \mathbf{g}, \mathbf{j}, \mathbf{m}$ both sexes together, $\mathbf{b}, \mathbf{e}, \mathbf{h}, \mathbf{k}, \mathbf{n}$ male subjects and $\mathbf{c}, \mathbf{f}, \mathbf{i}, \mathbf{l}, \mathbf{o}$ female subjects. Black circles were used for the data that were correlated to $\mathrm{HbAlc}$ concentration, while white circles were used when the relationship was not significant. HbA1c concentration was positively correlated with plasma copper concentration in both sexes together $(p=0.0034)$ and with plasma selenium concentration in both sexes together $(\mathrm{p}=0.0394)$ and in females $(\mathrm{p}=0.0150)$, while it was negatively correlated with the zinc/copper ratio in both sexes together $(\mathrm{p}=0.0428)$

together $(p=0.004$, Fig. 1g) and in males $(p=0.007$, Fig. 1h), but not in females and it did not correlate with HbA1c concentration in T2DM. The lack of an observable relationship between plasma magnesium concentration and $\mathrm{HbAlc}$ concentration in females with T1DM is surprising considering that magnesium concentration was lower in females with T1DM compared to males with T1DM (while no difference between the sexes could be seen in controls). Previous studies have shown that $\mathrm{HbA1c}$ levels correlate with magnesium excretion in females but not males (Brown et al. 1999; Lin and Huang 2015). A negative correlation between plasma magnesium concentration and $\mathrm{HbA} 1 \mathrm{c}$ concentration has also been reported in T2DM (Ramadass et al. 2015). Plasma selenium concentration correlated negatively with $\mathrm{HbA} 1 \mathrm{c}$ in T1DM when looking at both sexes together ( $p=0.031$, Fig. $1 \mathrm{j}$ ), as in a previous study (Ruiz et al. 1998), but there was no correlation when looking individually at males or females. In T2DM, plasma selenium concentration was correlated with $\mathrm{HbA} 1 \mathrm{c}$ concentration when looking at both sexes together ( $p=0.039$, Fig. $2 j)$ and in females $(p=0.015$, Fig. 21), contrary to a previous study that found a negative correlation with dysregulation of glucose and selenium concentration in males but not in females (Akbaraly et al. 2010). The plasma zinc/copper ratio was negatively correlated with $\mathrm{HbA} 1 \mathrm{c}$ in T1DM and T2DM when looking at both sexes together ( $p=0.0258$, Fig. $1 \mathrm{~m}$ and $\mathrm{p}=0.0428$, Fig. $2 \mathrm{~m}$ respectively) but not in males or females only. In previous publications, the zinc/copper ratio was also negatively correlated in T1DM and T2DM (Lin et al. 2014; AtariHajipirloo et al. 2016). Correlation of HbA1c concentration with total plasma metal concentrations could potentially be explained by glycation or oxidationassociated modifications of metal ion transport proteins (Abdelmagid et al. 2015), formation of glycocholate (anion of the bile acid glycholic acid) that can complex and excrete metals in bile (Atari-Hajipirloo et al. 2016) or abnormal insulin signalling leading to dysregulated metal homeostasis (McNair et al. 1982; Gommers et al. 2016).

Implications for dysregulated metal homeostasis in diabetes

Changes in total plasma metal concentrations in subjects with diabetes have the potential to negatively affect metabolic processes in the body. Low magnesium concentrations have been associated with an increased incidence of T1DM and T2DM and poor glycaemic control (Lin and Huang 2015; Ramadass et al. 2015). This may be due to the fact that magnesium ions $\left(\mathrm{Mg}^{2+}\right)$ are an essential cofactor in several processes. $\mathrm{Mg}^{2+}$ increases the affinity of insulin receptors for ATP and is thus essential for their auto-phosphorylation and tyrosine kinase activity, which results in $\mathrm{Mg}^{2+}$ sensitising cells to insulin (Guerrero-Romero and Rodriguez-Moran 2011; Gommers et al. 2016; Al Alawi et al. 2018). Thus chronically low $\mathrm{Mg}^{2+}$ concentrations can lead to insulin resistance (Guerrero-Romero and RodriguezMoran 2011; Gommers et al. 2016; Al Alawi et al. 2018). Furthermore, $\mathrm{Mg}^{2+}$ can also block the entry of $\mathrm{Ca}^{2+}$ into adipocytes through the L-type calcium channel. Therefore, when $\mathrm{Mg}^{2+}$ concentrations are insufficient, increased $\mathrm{Ca}^{2+}$ entry in adipocyte leads to inflammation, oxidative stress and increase insulin resistance (Nielsen et al. 2007; Gommers et al. 2016; Al Alawi et al. 2018). $\mathrm{Mg}^{2+}$ is also involved in the transport of glucose across membranes, it is a cofactor of several enzymes essential for carbohydrate oxidation (e.g. phosphotransferases and phosphohydrolases such as ATPases) and also plays a role in the release of insulin (Saris et al. 2000; Al Alawi et al. 2018). On the other hand, insulin decreases tubular reabsorption of $\mathrm{Mg}^{2+}$ and so high insulin levels (as in T2DM) could lead to reduced $\mathrm{Mg}^{2+}$ concentrations (McNair et al. 1982; Gommers et al. 2016). 
Selenium is mostly found in selenoproteins (as selenomethionine), of which many are important antioxidants (Roman et al. 2014). Therefore, high plasma concentrations of selenium may be due to oxidative stress mobilising high levels of selenoproteins. For example, the plasma concentration of selenoprotein $\mathrm{P}$ is known to be higher in T2DM subjects, a disease state associate with high levels of oxidative stress, and to be associated with insulin resistance (Misu et al. 2010; Ogawa-Wong et al. 2016). However, expression of plasma glutathione peroxidase (another selenoprotein) as well as serum albumin (which transports selenomethionine) are reduced in diabetes (Roman et al. 2010). Expression of selenoprotein $P$ is known to be reduced during inflammation (Nichol et al. 1998; Hesse-Bahr et al. 2000). Thus blood levels of selenium decrease during systemic inflammatory responses, which occur in T2DM (Wang et al. 2013). It has been hypothesised that the stages of the disease (impaired glucose tolerance or well-established T2DM) and the associated level of oxidative stress influences plasma selenium concentration (Rayman and Stranges 2013).

Zinc participates in the synthesis, storage and release of insulin. Notably, zinc is present in secretory vesicles within $\beta$-cells of the pancreas where it participates in the crystallisation/storage of insulin and is thus released alongside insulin into the plasma (Scott 1934; Chabosseau and Rutter 2016). Deficiency of zinc disrupts insulin homeostasis, resulting in a reduction of insulin secretion by $\beta$ cells (Fung et al. 2015). Zinc also stimulates lipogenesis and glucose uptake and reduced lipolysis in adipocytes (Coulston and Dandona 1980; Nishide et al. 2008). As zinc and copper homeostasis are closely linked, notably through competition during intestinal absorption and through shared transporter proteins such as serum albumin, a deficiency in one can affect the other (Osredkar and Sustar 2011). For example, zinc over-supplementation can lead to copper deficiency (Duncan et al. 2015). Impaired metabolism of zinc and copper are associated with a higher sensitivity to oxidative damage, as both zinc and copper are needed for the activity of the antioxidant enzyme superoxide dismutase, whose activity is reduced in T2DM (Sundaram et al. 1996). Thus, changes in the ratio of zinc/copper will affect enzyme catalysis and potentially further increase levels of free radicals, which are already increased in diabetes (Giacco and Brownlee 2010). In addition, copper is released from superoxide dismutase at high glucose concentrations due to fragmentation of the protein during glycation (Ookawara et al. 1992). Elevated copper levels in T2DM correlate with formation of reactive oxygen species (Masad et al. 2007). Insulin also reduces copper concentration in the liver through the regulation of at least one coppertransporting ATPase, ATP7B (Hilario-Souza et al. 2016). A reduction in insulin concentrations may thus result in an accumulation of copper in the liver.

Deficiency in magnesium, selenium and zinc have been shown to increase the risks of developing complicates associated with diabetes. Therefore, the effect of supplementation of these metals has been assessed. Magnesium supplementation was found to both improve diabetes management and to reduce the development of T2DM in individuals at risk (Rodriguez-Moran and Guerrero-Romero 2003; Hruby et al. 2014; Guerrero-Romero et al. 2015). Zinc supplementation has been shown to improve insulin and glucose levels in diabetes subjects and decrease the risk of developing T2DM (Jayawardena et al. 2012; Islam et al. 2016; Ranasinghe et al. 2018). However, selenium supplementation was not found to improve the risk of developing T2DM or the risk of developing complications in individuals with diabetes (Ogawa-Wong et al. 2016). This could be because the association between selenium concentrations and diabetes is not linear and that only individuals with selenium deficiency would benefit from supplementation, while individuals with sufficient selenium could increase their risk of developing T2DM if given an excess of this metal (Ogawa-Wong et al. 2016). Another explanation may be that the form of selenium used for supplementation in some studies offer variable bioavailability (Ogawa-Wong et al. 2016).

\section{Conclusion}

In conclusion, the study reported here is the first to examine zinc, copper, magnesium, selenium and HbA1c concentrations and sex-specific differences together in both T1DM, T2DM and controls. The homeostatic control of circulatory metal concentrations, in particular zinc, copper, magnesium and selenium, is essential for insulin regulation and energy metabolism. If plasma metal concentrations are altered in an individual with diabetes, the management of their condition will be more complex and they are more 
likely to develop complications. In addition, plasma metal concentrations are also influenced by insulin and glucose plasma levels. Thus, if those are not properly controlled, plasma metal concentrations are likely to become further dysregulated. Here we show that plasma magnesium concentration is altered to the highest degree in T1DM. In T2DM, plasma selenium and copper concentrations were significantly affected. This work increases our understanding of T1DM and T2DM pathogenesis and may have future implications for the management of diabetes.

Acknowledgements This work was supported by the British Heart Foundation (Grant codes: PG/15/9/31270 and FS/15/42/ 31556).

Open Access This article is distributed under the terms of the Creative Commons Attribution 4.0 International License (http:// creativecommons.org/licenses/by/4.0/), which permits unrestricted use, distribution, and reproduction in any medium, provided you give appropriate credit to the original author(s) and the source, provide a link to the Creative Commons license, and indicate if changes were made.

\section{References}

Abdelmagid SA, Clarke SE, Nielsen DE, Badawi A, El-Sohemy A, Mutch DM, Ma DW (2015) Comprehensive profiling of plasma fatty acid concentrations in young healthy Canadian adults. PLoS ONE 10(2):e0116195

Akbaraly TN, Arnaud J, Rayman MP, Hininger-Favier I, Roussel AM, Berr C, Fontbonne A (2010) Plasma selenium and risk of dysglycemia in an elderly French population: results from the prospective Epidemiology of Vascular Ageing Study. Nutr Metab (Lond) 7:21

Al Alawi AM, Majoni SW, Falhammar H (2018) Magnesium and human health: perspectives and research directions. Int J Endocrinol 2018:9041694

Atari-Hajipirloo S, Valizadeh N, Khadem-Ansari MH, Rasmi Y, Kheradmand F (2016) Altered concentrations of copper, zinc, and iron are associated with increased levels of glycated hemoglobin in patients with type 2 diabetes mellitus and their first-degree relatives. Int $\mathrm{J}$ Endocrinol Metab 14(2):e33273

Bleys J, Navas-Acien A, Guallar E (2007) Serum selenium and diabetes in U.S. adults. Diabetes Care 30(4):829-834

Brown IR, McBain AM, Chalmers J, Campbell IW, Brown ER, Lewis MJ (1999) Sex difference in the relationship of calcium and magnesium excretion to glycaemic control in type 1 diabetes mellitus. Clin Chim Acta 283(1-2):119-128

Chabosseau P, Rutter GA (2016) Zinc and diabetes. Arch Biochem Biophys 611:79-85

Coulston L, Dandona P (1980) Insulin-like effect of zinc on adipocytes. Diabetes 29(8):665-667
Duncan A, Yacoubian C, Watson N, Morrison I (2015) The risk of copper deficiency in patients prescribed zinc supplements. J Clin Pathol 68(9):723-725

Fung EB, Gildengorin G, Talwar S, Hagar L, Lal A (2015) Zinc status affects glucose homeostasis and insulin secretion in patients with thalassemia. Nutrients 7(6):4296-4307

Giacco F, Brownlee M (2010) Oxidative stress and diabetic complications. Circ Res 107(9):1058-1070

Gommers LM, Hoenderop JG, Bindels RJ, de Baaij JH (2016) Hypomagnesemia in type 2 diabetes: a vicious circle? Diabetes 65(1):3-13

Guerrero-Romero F, Rodriguez-Moran M (2011) Magnesium improves the beta-cell function to compensate variation of insulin sensitivity: double-blind, randomized clinical trial. Eur J Clin Invest 41(4):405-410

Guerrero-Romero F, Simental-Mendia LE, Hernandez-Ronquillo G, Rodriguez-Moran M (2015) Oral magnesium supplementation improves glycaemic status in subjects with prediabetes and hypomagnesaemia: a double-blind placebo-controlled randomized trial. Diabetes Metab 41(3):202-207

Hesse-Bahr K, Dreher I, Kohrle J (2000) The influence of the cytokines Il-1beta and INFgamma on the expression of selenoproteins in the human hepatocarcinoma cell line HepG2. BioFactors 11(1-2):83-85

Hilario-Souza E, Cuillel M, Mintz E, Charbonnier P, Vieyra A, Cassio D, Lowe J (2016) Modulation of hepatic copperATPase activity by insulin and glucagon involves protein kinase A (PKA) signaling pathway. Biochim Biophys Acta 1862(11):2086-2097

Hruby A, Meigs JB, O’Donnell CJ, Jacques PF, McKeown NM (2014) Higher magnesium intake reduces risk of impaired glucose and insulin metabolism and progression from prediabetes to diabetes in middle-aged americans. Diabetes Care 37(2):419-427

Islam MR, Attia J, Ali L, McEvoy M, Selim S, Sibbritt D, Akhter A, Akter S, Peel R, Faruque O, Mona T, Lona H, Milton AH (2016) Zinc supplementation for improving glucose handling in pre-diabetes: a double blind randomized placebo controlled pilot study. Diabetes Res Clin Pract 115:39-46

Jayawardena R, Ranasinghe P, Galappatthy P, Malkanthi R, Constantine G, Katulanda P (2012) Effects of zinc supplementation on diabetes mellitus: a systematic review and meta-analysis. Diabetol Metab Syndr 4(1):13

Kao WH, Folsom AR, Nieto FJ, Mo JP, Watson RL, Brancati FL (1999) Serum and dietary magnesium and the risk for type 2 diabetes mellitus: the Atherosclerosis Risk in Communities Study. Arch Intern Med 159(18):2151-2159

Kaur B, Henry J (2014) Micronutrient status in type 2 diabetes: a review. Adv Food Nutr Res 71:55-100

Laclaustra M, Navas-Acien A, Stranges S, Ordovas JM, Guallar E (2009) Serum selenium concentrations and diabetes in US adults: National Health and Nutrition Examination Survey (NHANES) 2003-2004. Environ Health Perspect 117(9):1409-1413

Larsson SC, Wolk A (2007) Magnesium intake and risk of type 2 diabetes: a meta-analysis. J Intern Med 262(2):208-214

Li Z, Wang C, Li L, Shao M, Wang L, Lv X, Gao C, Niu H, Li B (2018) The study on the correlation between six kinds of 
mineral elements and diabetes. Biol Trace Elem Res 183(2):226-232

Lin CC, Huang YL (2015) Chromium, zinc and magnesium status in type 1 diabetes. Curr Opin Clin Nutr Metab Care 18(6):588-592

Lin CC, Huang HH, Hu CW, Chen BH, Chong IW, Chao YY, Huang YL (2014) Trace elements, oxidative stress and glycemic control in young people with type 1 diabetes mellitus. J Trace Elem Med Biol 28(1):18-22

Lin CC, Tsweng GJ, Lee CF, Chen BH, Huang YL (2016) Magnesium, zinc, and chromium levels in children, adolescents, and young adults with type 1 diabetes. Clin Nutr 35(4):880-884

Luo YY, Zhao J, Han XY, Zhou XH, Wu J, Ji LN (2015) Relationship between serum zinc level and microvascular complications in patients with type 2 diabetes. Chin Med J (Engl) 128(24):3276-3282

Maret W (2017) Zinc in pancreatic islet biology, insulin sensitivity, and diabetes. Prev Nutr Food Sci 22(1):1-8

Masad A, Hayes L, Tabner BJ, Turnbull S, Cooper LJ, Fullwood NJ, German MJ, Kametani F, El-Agnaf OM, Allsop D (2007) Copper-mediated formation of hydrogen peroxide from the amylin peptide: a novel mechanism for degeneration of islet cells in type-2 diabetes mellitus? FEBS Lett 581(18):3489-3493

McNair P, Christensen MS, Christiansen C, Madsbad S, Transbol I (1982) Renal hypomagnesaemia in human diabetes mellitus: its relation to glucose homeostasis. Eur $\mathbf{J}$ Clin Invest 12(1):81-85

Misu H, Takamura T, Takayama H, Hayashi H, MatsuzawaNagata N, Kurita S, Ishikura K, Ando H, Takeshita Y, Ota T, Sakurai M, Yamashita T, Mizukoshi E, Yamashita T, Honda M, Miyamoto K, Kubota T, Kubota N, Kadowaki T, Kim HJ, Lee IK, Minokoshi Y, Saito Y, Takahashi K, Yamada Y, Takakura N, Kaneko S (2010) A liver-derived secretory protein, selenoprotein $\mathrm{P}$, causes insulin resistance. Cell Metab 12(5):483-495

Naka T, Kaneto H, Katakami N, Matsuoka TA, Harada A, Yamasaki Y, Matsuhisa M, Shimomura I (2013) Association of serum copper levels and glycemic control in patients with type 2 diabetes. Endocr J 60(3):393-396

Nichol C, Herdman J, Sattar N, O'Dwyer PJ, St JORD, Littlejohn D, Fell G (1998) Changes in the concentrations of plasma selenium and selenoproteins after minor elective surgery: further evidence for a negative acute phase response? Clin Chem 44(8 Pt 1):1764-1766

Nielsen FH, Milne DB, Gallagher S, Johnson L, Hoverson B (2007) Moderate magnesium deprivation results in calcium retention and altered potassium and phosphorus excretion by postmenopausal women. Magnes Res 20(1):19-31

Nishide M, Yoshikawa Y, Yoshikawa EU, Matsumoto K, Sakurai H, Kajiwara NM (2008) Insulinomimetic Zn(II) complexes as evaluated by both glucose-uptake activity and inhibition of free fatty acids release in isolated rat adipocytes. Chem Pharm Bull (Tokyo) 56(8):1181-1183

Ogawa-Wong AN, Berry MJ, Seale LA (2016) Selenium and metabolic disorders: an emphasis on type 2 diabetes risk. Nutrients 8(2):80

Ookawara T, Kawamura N, Kitagawa Y, Taniguchi N (1992) Sitespecific and random fragmentation of $\mathrm{Cu}, \mathrm{Zn}$-superoxide dismutase by glycation reaction. Implication of reactive oxygen species. J Biol Chem 267(26):18505-18510

Osredkar J, Sustar N (2011) Copper and zinc, biological role and significance of copper/zinc imbalance. J Clinic Toxicol S3:001-018

Ramadass S, Basu S, Srinivasan AR (2015) SERUM magnesium levels as an indicator of status of Diabetes Mellitus type 2. Diabetes Metab Syndr 9(1):42-45

Ranasinghe P, Wathurapatha WS, Galappatthy P, Katulanda P, Jayawardena R, Constantine GR (2018) Zinc supplementation in prediabetes: a randomized double-blind placebocontrolled clinical trial. J Diabetes 10(5):386-397

Rayman MP, Stranges S (2013) Epidemiology of selenium and type 2 diabetes: can we make sense of it? Free Radic Biol Med 65:1557-1564

Rodriguez-Moran M, Guerrero-Romero F (2003) Oral magnesium supplementation improves insulin sensitivity and metabolic control in type 2 diabetic subjects: a randomized doubleblind controlled trial. Diabetes Care 26(4):1147-1152

Roman M, Lapolla A, Jitaru P, Sechi A, Cosma C, Cozzi G, Cescon P, Barbante C (2010) Plasma selenoproteins concentrations in type 2 diabetes mellitus-a pilot study. Transl Res 156(4):242-250

Roman M, Jitaru P, Barbante C (2014) Selenium biochemistry and its role for human health. Metallomics 6(1):25-54

Ruiz C, Alegria A, Barbera R, Farre R, Lagarda J (1998) Selenium, zinc and copper in plasma of patients with type 1 diabetes mellitus in different metabolic control states. J Trace Elem Med Biol 12(2):91-95

Sanjeevi N, Freeland-Graves J, Beretvas SN, Sachdev PK (2018) Trace element status in type 2 diabetes: a metaanalysis. J Clin Diagn Res 12(5):OE01-OE08

Saris NE, Mervaala E, Karppanen H, Khawaja JA, Lewenstam A (2000) Magnesium. An update on physiological, clinical and analytical aspects. Clin Chim Acta 294(1-2):1-26

Scott DA (1934) Crystalline insulin. Biochem J 28(4):1592-1602

Sundaram RK, Bhaskar A, Vijayalingam S, Viswanathan M, Mohan R, Shanmugasundaram KR (1996) Antioxidant status and lipid peroxidation in type II diabetes mellitus with and without complications. Clin Sci (Lond) 90(4):255-260

Terres-Martos C, Navarro-Alarcon M, Martin-Lagos F, De La Serrana HLG, Perez-Valero V, Lopez-Martinez MC (1998) Serum zinc and copper concentrations and $\mathrm{Cu} / \mathrm{Zn}$ ratios in patients with hepatopathies or diabetes. J Trace Elem Med Biol 12(1):44-49

Wang X, Bao W, Liu J, Ouyang YY, Wang D, Rong S, Xiao X, Shan ZL, Zhang Y, Yao P, Liu LG (2013) Inflammatory markers and risk of type 2 diabetes: a systematic review and meta-analysis. Diabetes Care 36(1):166-175

Wang XL, Yang TB, Wei J, Lei GH, Zeng C (2016) Association between serum selenium level and type 2 diabetes mellitus: a non-linear dose-response meta-analysis of observational studies. Nutr J 15(1):48

Publisher's Note Springer Nature remains neutral with regard to jurisdictional claims in published maps and institutional affiliations. 